\title{
Combined Analytical Approaches to Standardize and Characterize Biomaterials Formulations: Application to Chitosan-Gelatin Cross-Linked Hydrogels
}

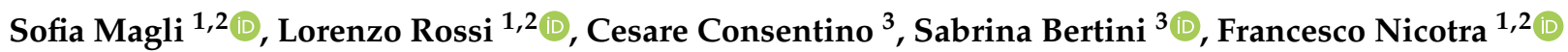 \\ and Laura Russo $1,2,4, * \mathbb{D}$ \\ 1 Department of Biotechnology and Biosciences, University of Milano-Bicocca, 20126 Milan, Italy; \\ s.magli1@campus.unimib.it (S.M.); 1.rossi58@campus.unimib.it (L.R.); francesco.nicotra@unimib.it (F.N.) \\ 2 BioNanoMedicine Center, University of Milano-Bicocca, 20126 Milan, Italy \\ 3 G. Ronzoni Institute for Chemical and Biochemical Research, 20126 Milan, Italy; cosentino@ronzoni.it (C.C.); \\ bertini@ronzoni.it (S.B.) \\ 4 CÚRAM SFI Research Centre for Medical Devices, National University of Ireland Galway, Galway, Ireland \\ * Correspondence: laura.russo@unimib.it; Tel.: +39-0264483462
}

check for

updates

Citation: Magli, S.; Rossi, L.; Consentino, C.; Bertini, S.; Nicotra, F.;

Russo, L. Combined Analytical Approaches to Standardize and Characterize Biomaterials

Formulations: Application to Chitosan-Gelatin Cross-Linked Hydrogels. Biomolecules 2021, 11, 683. https://doi.org/10.3390/ biom 11050683

Academic Editor: Antonio Evidente

Received: 13 April 2021

Accepted: 29 April 2021

Published: 1 May 2021

Publisher's Note: MDPI stays neutral with regard to jurisdictional claims in published maps and institutional affiliations.

Copyright: (c) 2021 by the authors. Licensee MDPI, Basel, Switzerland. This article is an open access article distributed under the terms and conditions of the Creative Commons Attribution (CC BY) license (https:/ / creativecommons.org/licenses/by/ $4.0 /)$.

\begin{abstract}
A protocol based on the combination of different analytical methodologies is proposed to standardize the experimental conditions for reproducible formulations of hybrid hydrogels. The final hybrid material, based on the combination of gelatin and chitosan functionalized with methylfuran and cross-linked with 4-arm-PEG-maleimide, is able to mimic role, dynamism, and structural complexity of the extracellular matrix. Physical-chemical properties of starting polymers and finals constructs were characterized exploiting the combination of HP-SEC-TDA, UV, FT-IR, NMR, and TGA.
\end{abstract}

Keywords: hybrid biomaterials; gelatin; chitosan; Diels Alder; hydrogels; extracellular matrix

\section{Introduction}

The design of new advanced hybrid hydrogels for tissue engineering is today a matter of great interest for a plethora of applications [1-6]. The advancement in fabrication methodologies, for instance, 3D printing and bioprinting, requires an increased knowledge of the molecular composition of the employed biopolymers, guaranteeing an improved control of their effect on extracellular matrix (ECM) signaling and remodeling [7-10]. The combination of different classes of biopolymers, such as proteins and polysaccharides, characterized by different impacts on cells viability and behavior, is a promising approach to build up structures mimicking the complex ECM architectures and role [11-14]. To accurately reproduce the ECM properties, new hybrid biomaterials made of natural and/or synthetic polymers are usually designed and synthesized by covalent cross-linking, taking advantage of functional groups already present in the polymer chains or properly introduced [15-17]. Furthermore, the combination of different polymers increases the system complexity, providing additional motifs for fine control over crucial features for the desired applications [18]. Thus, the physical features, 3D architecture, stiffness properties, and biochemical composition can be designed in a customizable way to strategically promote specific cues finely tuning cell behavior [19,20]. However, the employment of heterogeneous polymers combined with the assessment of new cross-linking methodologies embraces some limitations in standardization of the ultimate constructs. In order to overcome this limitation, a control over reaction kinetics is required, besides a deep characterization of the final product, performed by combining multiple techniques.

The cross-linking method is, for multiple reasons, a crucial aspect to be assessed. For such purpose, several click reactions have been investigated, exploiting linkers of different length bearing functional groups complementary to those already present in 
polymers backbone or previously chemically introduced [14,21-24]. Among the established approaches, Diels Alder reaction has already been widely used with a significant assortment of biopolymers to control cross-linking and conjugations between polymers displaying diene and dienophile moieties [25-34]. However, the reported studies are often focused on homopolymer formulations [32,35-37]. In our group, a hybrid hydrogel was developed employing gelatin and chitosan functionalized with methylfuran and then cross-linking them by Diels Alder reaction with 4-arm-PEG10K-maleimide [15,34]. The obtained hydrogel (GelChiDA) showed stability over time in cell culture conditions, in both 3D scaffolds and 3D-bioprinted cell-embedded formulations. The development of such promising hydrogel requires, however, standardization of the process in order to guarantee reproducibility of homogeneous batches, which is critical for the translation to frontier research. Well-assessed protocols are needed to monitor the kinetics of the reactions, the structural features, and the characterization of the produced hydrogel after cross-linking reaction. Considering the complexity of the system, the reaction kinetics and physical-chemical properties are arduous to investigate. Here, we report the combination of different analytical methodologies, to follow the kinetics of GelChiDA formation and to characterize the final construct in terms of physical-chemical properties. To this purpose, we exploited the combination of HP-SEC-TDA, UV, FT-IR, NMR, and thermogravimetric analysis.

\section{Materials and Methods}

Water-soluble chitosan was purchased from Biosynth Carbosynth (Compton, UK). All other chemicals were purchased from Merck KGaA (Darmstadt, Germany), unless differently stated, and used as received without further purifications. Deionized water (conductivity less than $0.1 \mathrm{~S}$ ) was prepared with an inverse osmosis system (Culligan, Milan, Italy). PolyCAL TM Pullulan std-57k was used (Malvern Instruments Ltd., Malvern, UK). The reagent grades were $98 \%$.

\subsection{Sample Preparations}

Functionalization of Gelatin and Chitosan with methylfuran. Gelatin and chitosan were functionalized with methylfuran as already reported [15]. Briefly, both polymers were reacted with 5-methylfurfural and $\mathrm{NaBH}_{3} \mathrm{CN}$ performing a reductive amination. The functionalized polymers (polymer-MFs) were dialyzed in ionic conditions and against $\mathrm{H}_{2} \mathrm{O}$.

General procedure for hydrogel formation. The obtained polymer-MFs were freeze dried and employed for the hydrogel formation: $33 \mathrm{mg}$ of gelatin-MF and $17 \mathrm{mg}$ of chitosanMF were dissolved in $1 \mathrm{~mL}$ of PBS pH 7.4 at $310 \mathrm{~K}$. After total dissolution of polymers, $2.6 \mathrm{mg}$ of 4-arm-PEG10K-maleimide was added, and the solution was stirred until its dissolution and then left at $310 \mathrm{~K}$ for $3 \mathrm{~h}$ allowing the hydrogel formation.

\subsection{Analytical Methods}

Molecular weight distribution by size exclusion chromatography with triple detector array (HP-SEC-TDA) analysis. Evaluation of the molecular weight distribution of gelatin and gelatin-MF samples was performed by size exclusion chromatography coupled with a multi-detector system (refractive index, right and low angle light scattering, viscometer, Viscotek mod. 305 Triple Detector Array, Malvern Instruments Ltd., Malvern, UK) [38]. In particular, the analysis of gelatin was performed at $313 \mathrm{~K}$, using a TSKPWXL column (Tosoh Bioscience, $7.8 \mathrm{~mm}$ ID $\times 30 \mathrm{~cm}$ ). A total of $0.01 \mathrm{M} \mathrm{K}$ buffer $+0.125 \mathrm{M} \mathrm{NaNO}_{3}$, containing $0.05 \% \mathrm{NaN} 3$, pre-filtered using $0.22 \mathrm{~mm}$ filter (Millipore), was used as mobile phase at a flow rate of $0.6 \mathrm{~mL} / \mathrm{min}$. Briefly, $0.1 \mathrm{~mL}$ of sample were injected at about $1 \mathrm{mg} / \mathrm{mL}$. Chromatographic conditions for gelatin-MF were set up using two TSKPWXL columns in series (Tosoh Bioscience, $7.8 \mathrm{~mm}$ ID $\times 30 \mathrm{~cm}, \mathrm{~V}_{0} 6 \mathrm{~mL}$, Vt $11 \mathrm{~mL}$ each one) with an aqueous solution of $0.2 \mathrm{M} \mathrm{NaNO}_{3}$ added with $0.05 \% \mathrm{NaN}_{3}$ pre-filtered onto $0.22 \mathrm{~mm}$ filter (Millipore), used as mobile phase at a flow rate of $0.6 \mathrm{~mL} / \mathrm{min}$. Then, 
$0.1 \mathrm{~mL}$ of each sample was injected at about $1 \mathrm{mg} / \mathrm{mL}$. For both methods, columns, injector, and detectors were maintained at $313 \mathrm{~K}$. For chitosan and chitosan-MF samples, chromatographic conditions were set up using two gel TSKWXL mixed bed columns (Tosoh Bioscience, $7.8 \mathrm{~mm} \mathrm{ID} \times 30 \mathrm{~cm}, \mathrm{~V}_{0} 6 \mathrm{~mL}, \mathrm{Vt} 11 \mathrm{~mL}$ ) with an aqueous solution of $0.3 \mathrm{M}$ sodium acetate and $0.3 \mathrm{M}$ acetic acid $(\mathrm{pH} 4)$ added with $0.05 \% \mathrm{NaN}_{3}$ pre-filtered onto $0.22 \mathrm{~mm}$ filter (Millipore) used as mobile phase at a flow rate of $0.6 \mathrm{~mL} / \mathrm{min}$. Further, $0.1 \mathrm{~mL}$ of each sample were injected at about $1 \mathrm{mg} / \mathrm{mL}$. Columns, injector, and detectors were maintained at $313 \mathrm{~K}$. The detector was calibrated with the Pollulan narrow standard of known Mw, polydispersity, and intrinsic viscosity (Malvern Instruments Ltd., Malvern, UK). The chromatogram elaboration was performed using OmniSEC software version 4.6.2. For calculations, a differential refractive index increment $(\mathrm{dn} / \mathrm{dc})$ value of 0.180 for gelatin and its derivates and of 0.167 for chitosan and its derivates were used for converting RI voltages to solute concentration at each data slice across a chromatographic peak, as previously described [38-40]. The obtained $\mathrm{Mw}$ ad $\mathrm{Mn}$ values were rounded to the nearest $1000 \mathrm{Da}$.

FTIR-ATR. Each sample was reduced as powders and FT-IR spectra were recorded in attenuated total reflection ATR mode using PerkinElmer Spectrum 100 FTIR Spectrometer (Milan, Italy). The absorption spectral range was collected between 4000 and $650 \mathrm{~cm}^{-1}$ at a spectral resolution of $2 \mathrm{~cm}^{-1}$ and 40 scans. FT-IR analysis was performed at different time points on freeze-dried samples.

UV-VIS Measures. The UV-VIS absorption-solution spectra of the reaction was followed in real time from $\mathrm{T} 0$ to $3 \mathrm{~h}$. The spectra were recorded in the spectral region of 200-500 nm using JASCO V-770 spectrophotometer (Cremella, Italy). Briefly, $1 \mathrm{~mL}$ of the hybrid GelChiDA starting solution was transferred into a $0.1 \mathrm{~mm}$ optical path quartz cuvette, and the spectra were acquired between $\mathrm{T} 0$ and $3 \mathrm{~h}$.

Procedure for hydrogel formation for ${ }^{1} \mathrm{H}-\mathrm{NMR}$ and Diffusion Order Spectroscopy NMR analysis. Gelatin-MF (33 mg) and chitosan-MF (17 mg) were dissolved in $1 \mathrm{~mL}$ deuterated PBS (dPBS) pH 7.4 at $310 \mathrm{~K}$ and vortexed to help the solubilization. Once a solution was obtained, $2.6 \mathrm{mg}$ of 4-arm-PEG10K-maleimide was added and the sample was immediately transferred in an NMR tube and the analysis was started.

${ }^{1} \mathrm{H}$ NMR kinetics experiments. ${ }^{1} \mathrm{H}-\mathrm{NMR}$ spectra were acquired using a Varian $400 \mathrm{MHz}$ Mercury instrument (Palo Alto, Santa Clara, CA, USA), operating at a proton frequency equal to $400 \mathrm{MHz}$ at $310 \mathrm{~K}$. Chemical shifts were referenced towards 3(trimethylsilyl)propionic-2,2,3,3- $\mathrm{d}_{4}$ acid sodium salt $(0 \mathrm{ppm})$. Spectra of polymers were acquired setting the pulse angle at $90^{\circ}$ and the relaxion delay at $2 \mathrm{~s}$, while the number of scans varied between 160 and 240 depending on the signal-to-noise ratio. The hydrogel kinetics of gelatin with chitosan was monitored by the acquisition of ${ }^{1} \mathrm{H}-\mathrm{NMR}$ spectra over time. ${ }^{1} \mathrm{H}-\mathrm{NMR}$ spectra were acquired using 16 scans, with a pulse angle of $90^{\circ}$ and relaxation delay of $20 \mathrm{~s}$. Every $10 \mathrm{~min}$, a spectrum was recorded for a total of $32 \mathrm{spec}-$ tra. All NMR spectra were acquired in deuterated PBS, $\mathrm{pH} 7.4$, containing $0.05 \%$ wt of 3-(trimethylsilyl)propionic-2,2,3,3- $\mathrm{d}_{4}$ acid sodium salt.

Diffusion Order Spectroscopy NMR (DOSY). DOSY experiments of both the hydrogel and the blended polymers were performed with Bruker ADVANCE NEO, $500 \mathrm{MHz}$ spectrometer (Bruker, Karlsruhe, Germany) equipped with a $5 \mathrm{~mm}$ TCI cryo-genic probe, at $310 \mathrm{~K}$, and measured using the 2D stimulated echo sequence using bipolar gradient pulse for diffusion. The hydrogel has been prepared as reported in material and method section, whereas the blended polymers were prepared in identical concentrations and conditions but without the 4-arm-PEG10K-maleimide, in ${ }^{1} \mathrm{H}$ dimension of the diffusion experiments, a sweep width of $20 \mathrm{ppm}$ was used. The gradient pulse ( $\delta$ ) was set to $5 \mathrm{~ms}$, and the diffusion time $(\Delta)$ was set to $300 \mathrm{~ms}$. The 2D DOSY experiments were acquired using the 2D-stimulated echo sequence with bi-polar gradient pulse for diffusion with gradients varying linearly from $5 \%$ to $95 \%$ in 32 steps with 16 scans per step. The gradient pulse $(\delta)$ and the diffusion time $(\Delta)$ were set to 5 and $300 \mathrm{~ms}$, respectively. Spectra were processed by Top-Spin 4.0.6 software, supplied by the manufacturer. A 1-Hz line broadening Lorenzian 
function was applied, and each row was phased and baseline was corrected before Fourier transformation in the F2 dimension. The diffusion coefficients $\mathrm{D}$ for the $1 \mathrm{H}$ dimension in which molecules with different diffusion coefficients correlate to two distinct signals were calculated with Bruker Dynamic Center 2.5 (Bruker, Karlsruhe, Germany). The fitted function used is $I=I_{0}\left(-D \cdot x^{2} \cdot \gamma^{2} \cdot \delta^{2}\right) \cdot\left(\Delta-\frac{\delta}{3}\right)$ where $I$ is the observed intensity, $I_{0}$ is the reference intensity, $x$ is the gradient strength, $D$ is the diffusion coefficient, $\gamma$ is the gyromagnetic ratio of the observed nucleus, $\delta$ is the length of the gradient, and $\Delta$ is the diffusion time.

TGA analysis. TGA of the starch-gelatin samples was performed using a Mettler Toledo TGA/DSC1 Star-e System. Samples of $\sim 10 \mathrm{mg}$ were subjected to temperatures ranging from 303 to $1073 \mathrm{~K}$ at a heating rate of $10 \mathrm{~K} \mathrm{~min}^{-1}$. Nitrogen was used as purge gas at a flow rate of $50 \mathrm{~mL} \mathrm{~min}^{-1}$. Samples were freeze dried prior detection.

\section{Results}

Type A gelatin from skin porcine and water-soluble chitosan were employed as starting biopolymers [41-44]. These biopolymers were previously investigated in our group for the development of 3D bioprintable GelChiDA hydrogels for 3D cell cultures and tissue engineering purposes [15]. Briefly, both gelatin and chitosan were functionalized with methylfuran (MF), exploiting, respectively, the amino group of lysine residues of gelatin and the amino group of chitosan by reductive amination. The introduced dienes subsequently undergo cross-linking exploiting a Diels-Alder cycloaddition reaction using as dienophile a commercially available 4-arm-PEG10K-maleimide (Scheme 1), to obtain a heteropolymers based hydrogels [15]. As reported in a previous work, this cross-linking approach resulted in a highly reproducible, biocompatible, affordable, and easy to characterize product.

(a)

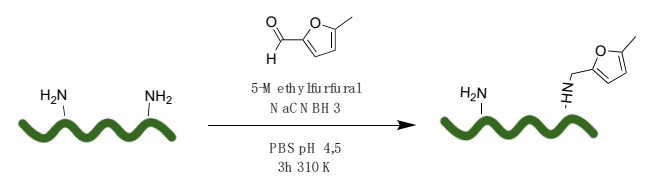

(b)

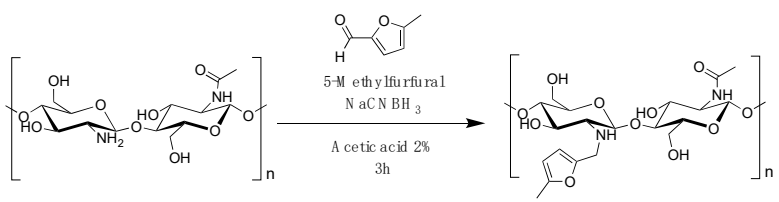

(c)

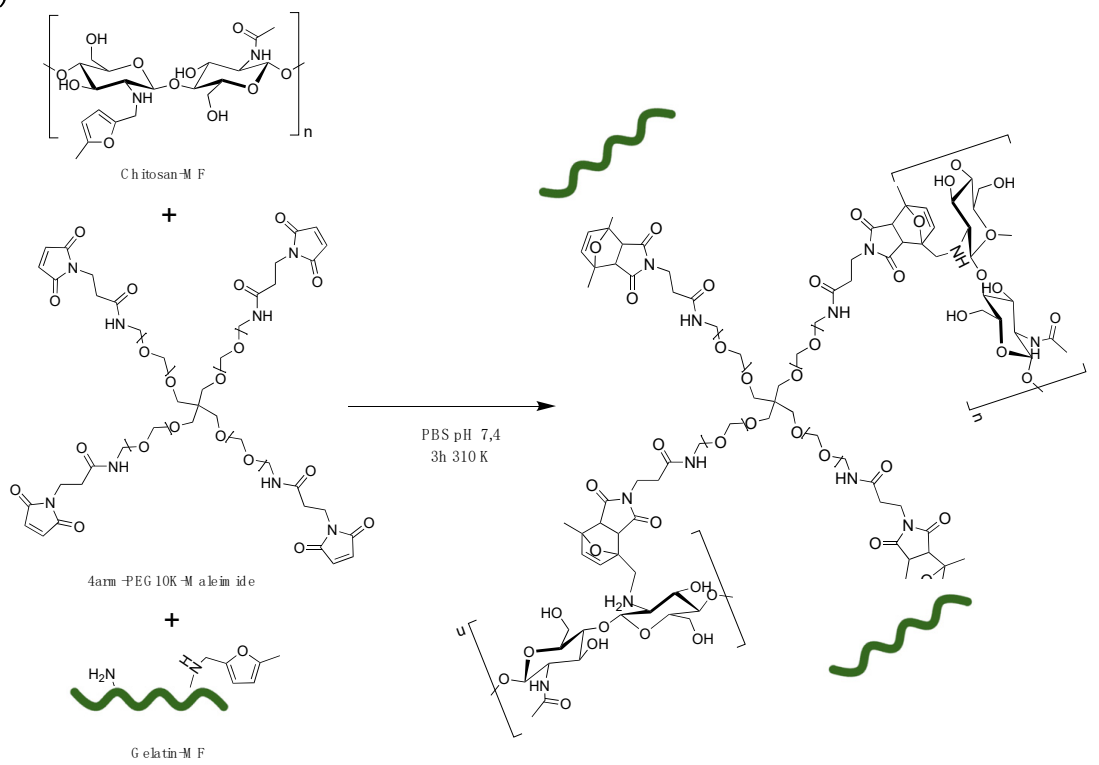

Scheme 1. Synthetic scheme of chitosan (a) and gelatin (b) functionalization with 5-methylfuran and GelChiDA hybrid biopolymer cross-linking reaction (c). 
3.1. Molecular Weight Distribution by Size Exclusion Chromatography with Triple Detector Array (HP-SEC-TDA) Analysis

Considering the different chemical structure of chitosan and gelatin, molecular weight distribution analysis was performed on the polymer-MFs to better define the features of the functionalized starting polymers. Size exclusion chromatography (or HP-SEC-TDA) coupled with analysis on multi-detector systems to capture light scattering, refractive index, and viscosity were employed to characterize gelatin-MF and chitosan-MF compared to the starting untreated counterparts. HP-SEC-TDA was used extensively to obtain molecular weight distribution of polymers and proteins; this method does not require any chromatographic calibration and is suitable to analyze polymers of different natures and weights. The solvents used in the analysis range from near-physiological to very harsh conditions, including high salts and/or strong surfactants concentration. The solvent systems induce complete denaturation or loss of higher orders protein structure of gelatin. In this way, good separations are obtained, and accurate molecular weight information can be acquired. Chromatographic profiles of gelatin and gelatin-MF are visible in Figure 1a,b, with a large bell-shape chromatographic peak, with a quite high polydispersion index value.

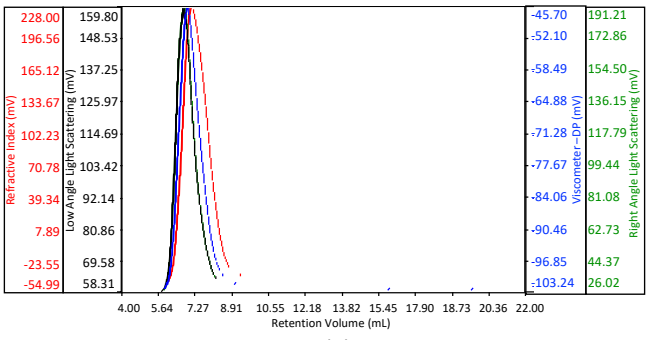

(a)

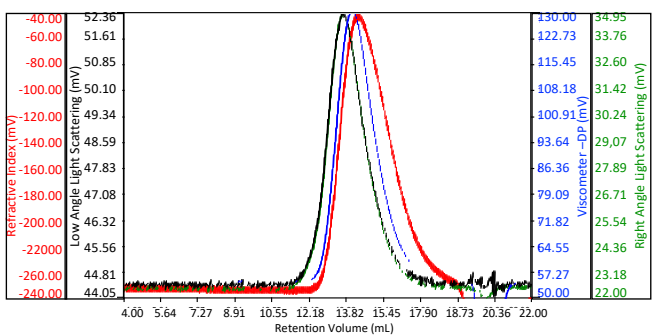

(d)

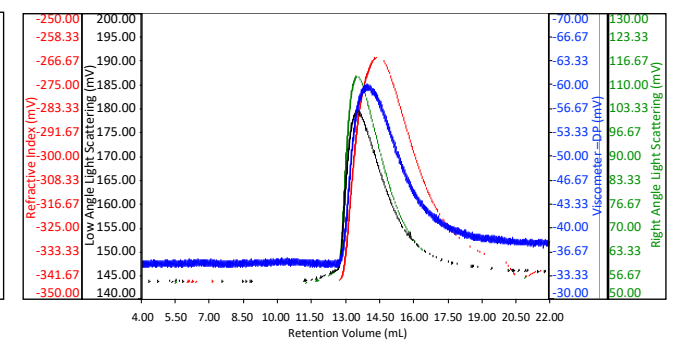

(b)

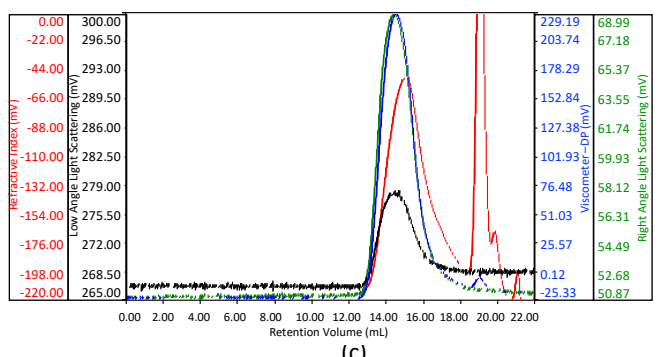

(c)

Figure 1. High-performance size exclusion chromatography on line with a triple detector array (HPSEC-TDA) chromatogram of gelatin (a) and gelatin-methylfuran (MF) (b) chitosan (c) chitosan-MF (d) samples (red-refractive index; blue-viscometer; green—right-angle laser light scattering and black-low angle light scattering).

The refractive index elution profiles of the MF derivates (Figure 1b,d) show the enlargement of the profile in the low-molecular-weight chains side respect to gelatin and chitosan (Figure 1a,c), suggesting a possible interaction with the stationary phase. Anyway, this phenomenon does not influence the molecular weight distribution evaluation.

The average results of two analyses for gelatin and gelatin-MF, in terms of $\mathrm{Mw}$ (weight average molecular weight), Mn (number average molecular weight), dispersity $\mathrm{D}$ (expressed as $\mathrm{Mw} / \mathrm{Mn}$ ratio), and intrinsic viscosity $((\eta), \mathrm{dL} / \mathrm{g})$ values are reported in Table 1 . The obtained results reveal high variations in molecular weight distribution and viscosity between the gelatin samples analyzed. 
Table 1. Main results of the high-performance size exclusion chromatography on line with a triple detector array (HP-SEC-TDA) analysis for the gelatin and gelatin-methylfuran (MF) samples.

\begin{tabular}{ccccc}
\hline Sample & Mw kDa & Mn kDa & D (Mw/Mn) & ( $)$ dL/g \\
\hline Gelatin & 210 & 115 & 1.9 & 0.51 \\
Gelatin-MF & 196 & 140 & 1.4 & 0.46 \\
\hline
\end{tabular}

The obtained results reveal no significant variations in molecular weight values and viscosity between the gelatin and gelatin-MF samples analyzed. As expected, the derivatization of amino groups of lysine to $\mathrm{N}$-methyl-(5-methylfurfuyl), after reductive amination with 5-methylfurfural, does not significatively change the molecular weight values.

Chromatographic profiles of chitosan and chitosan-MF are shown in Figure 1c,d: in both cases the sample is eluted between 11 and $18 \mathrm{~mL}$, with a large asymmetric bell-shape chromatographic peak, indicating a quite high polydispersion index value. Here, the comparable values obtained confirm the maintenance of starting chitosan structure and molecular weight after the reaction with 5-methylfurfural.

The average results of two analyses, in terms of Mw, are reported in Table 2.

Table 2. Main results of the HP-SEC-TDA analysis for the chitosan and chitosan-MF samples.

\begin{tabular}{ccccc}
\hline Sample & Mw kDa & Mn kDa & D (Mw/Mn) & $(\boldsymbol{\mu}) \mathbf{d L} / \mathbf{g}$ \\
\hline Chitosan & 47.5 & 28.7 & 1.7 & 1.5 \\
Chitosan-MF & 57.0 & 30.0 & 1.9 & 1.7 \\
\hline
\end{tabular}

\subsection{UV and FT-IR Analysis}

UV analysis allows to monitor the GelChiDA hybrid hydrogel formation by measuring the maleimide peak at $293 \mathrm{~nm}$ from T0 to T3 $\mathrm{h}$ [45]. This absorbance change is associated to the maleimide peak decrease due to Diels-Alder reaction between furan and maleimide moieties. This absorbance change is associated to the maleimide peak decrease due to Diels-Alder reaction between furan and maleimide moieties, leading to the cross-linked product formation, as shown in Figure 2a [30,45-47].

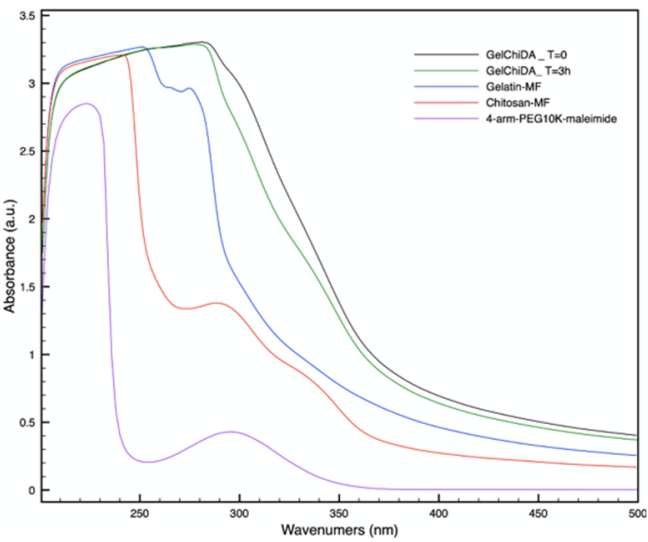

(a)

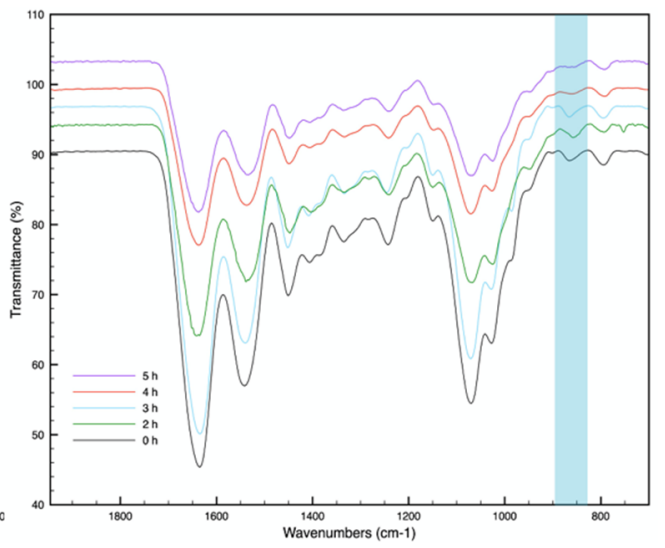

(b)

Figure 2. (a) UV spectra of cross-linking reaction in real time and (b) comparison of FT-IR spectra at different time points.

Figure $2 \mathrm{~b}$ shows the evolution of IR spectra versus time of the reaction gelatin-MF and chitosan-MF with 4-arm-PEG10K-maleimide in PBS pH 7.4. We focused our attention on the signal at $862 \mathrm{~cm}^{-1}$, attributed to $\mathrm{C}-\mathrm{H}$ vibration of double bond in furan ring. The peak shows a decrease in intensity over the time during the reaction, meaning the formation of the Diels-Alder adduct and the consequent cross-linking [48,49]. 


\section{3. ${ }^{1} H$-NMR Characterization}

Chitosan-MF and gelatin-MF were characterized by ${ }^{1} \mathrm{H}-\mathrm{NMR}$ analysis to evaluate the functionalization degree and the peaks assignment [50-53] (Figures S1 and S5). In-depth NMR characterization via ${ }^{13} \mathrm{C}-\mathrm{NMR}, \mathrm{HSQC}$, and gHMBC analysis of starting materials can be found in the Supplementary Materials. Particular attention has been devoted to the reacting groups. Each peak of furan of both chitosan-MF and gelatin-MF have been identified in both the ${ }^{1} \mathrm{H}$ and ${ }^{13} \mathrm{C}$ spectra comparing HSQC and gHMBC analysis, for shortand long-range correlations. Furthermore, peaks of interest have been characterized in order to determine the proper functionalization of the biopolymers prior to the hydrogel formulation. The peaks identified in both polymers have then been employed to follow the appropriate signals during the real-time NMR analysis in solution. Spectral variations, such as reduction in peak intensities, line broadening, and chemical shift changes, are all aspects monitored to assess the degree of cross-linking reaction and to determinate the reaction kinetics. The reaction conditions were replicated using deuterated PBS at $\mathrm{pH} 7.4$ and $310 \mathrm{~K}$ in an NMR tube to follow the cross-linking kinetics until completion. Different representative spectra intervals have been considered. Figure 3a shows the spectra of the hydrogel formation in real time.

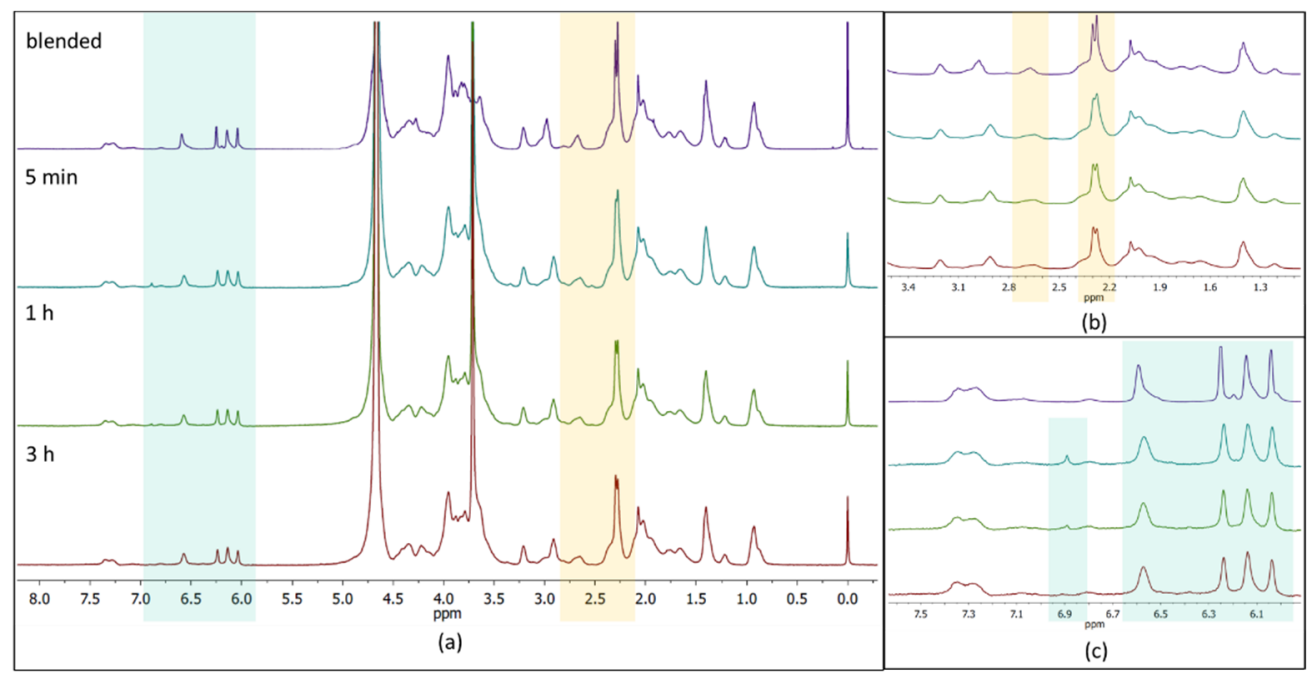

Figure 3. Comparison between ${ }^{1} \mathrm{H}$ NMR spectrum of blended polymers and real-time gel formation at $5 \mathrm{~min}, 1 \mathrm{~h}$, and $3 \mathrm{~h}(\mathbf{a})$ with a focus on the area between 1-3.5 (b) and 6-7.5 ppm (c).

The kinetics was monitored through the acquisition of several ${ }^{1} \mathrm{H}$ solution NMR spectra as reported in the Materials and Method section. After mixing the two polymers, the ${ }^{1} \mathrm{H}-\mathrm{NMR}$ spectrum shows the characteristic signal of 4-arm-PEG10K-Maleimide at 6.9 ppm [54] (Figure 3a,c). Observing the comparison of different timepoints of the kinetics, the signal of the double bond of maleimide decreases and finally, disappears after $3 \mathrm{~h}$ suggesting the completion of the reaction $[55,56]$. Simultaneously, the MF peaks between 6.0 and $6.6 \mathrm{ppm}$ decrease, indicating a partial conversion of furan groups into the adduct with respect to the stoichiometry of the reaction (Figure S9). Moreover, the peak influenced by the signal of $\mathrm{H}-2$ of chitosan-MF at $2.6 \mathrm{ppm}(\mathrm{CHN})$ shifts by experiencing a change in the neighboring chemical environment, coherently with the reaction advance. Because of the moderate intensity of the new peak and the very slight shift downfield, such change in that region of the spectrum is only observed by integrating different areas of the overlapping signals, as shown in Figure S9. The peaks at 2.2 and 2.3 ppm, assigned to the methyl groups on methylfuran moieties of both polymers, undergo a shift as highlighted in the Figure 3b. To further analyze the cross-linked GelChiDA hybrid hydrogel and discriminate it with respect to the blended components, pulsed field gradient (PFG) diffusion ordered spectroscopy (DOSY) has been performed. The DOSY experiment is represented in a $2 \mathrm{D}$ 
spectrum in Figure 4, with chemical shift along one axis and the diffusion coefficients along the other. As shown in Figure 4a, just one population is detectable for the GelChiDA hydrogel (red line), whereas the blended chitosan-MF and gelatin-MF polymers (blue line) are characterized by different diffusive fronts.

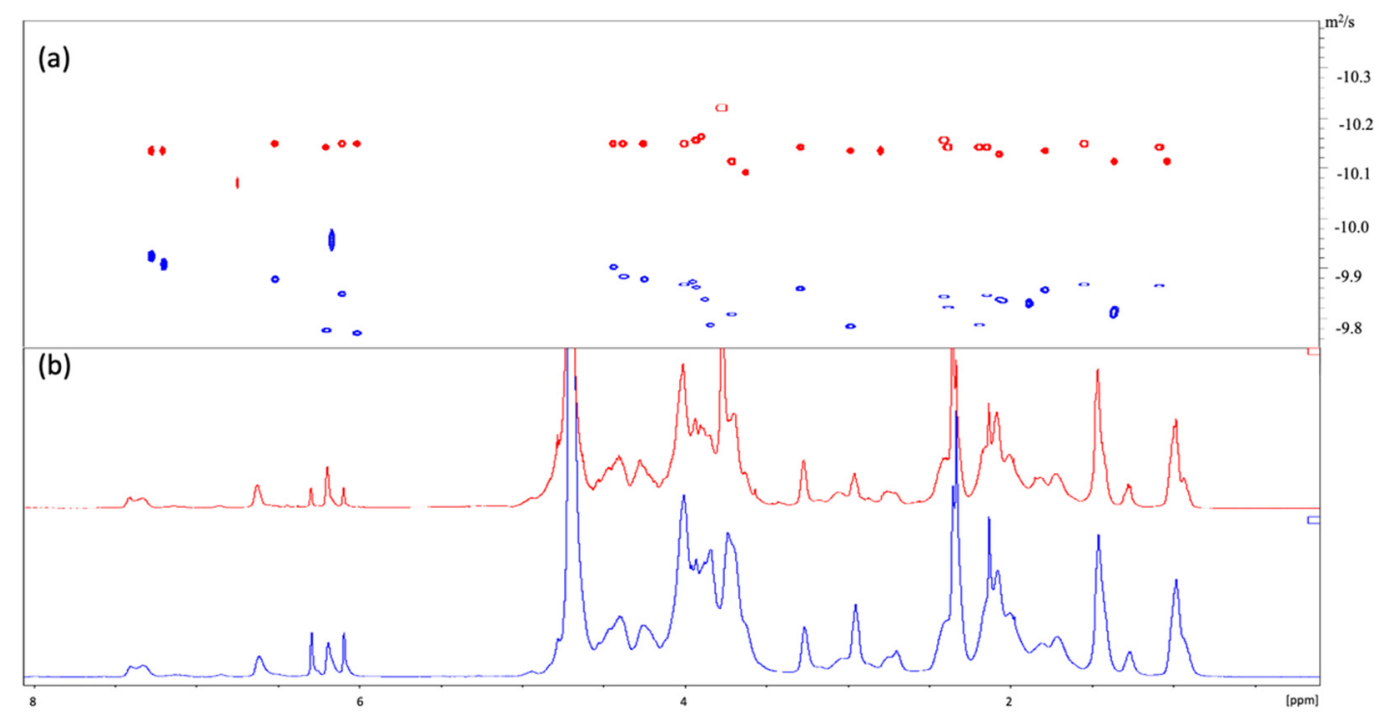

Figure 4. (a) Diffusion ordered spectroscopy NMR (DOSY) and (b) $1 \mathrm{H}$ spectra of blend (blue) and hydrogel (red) at the end of kinetics.

In the blend sample, the diffusion values are lower if compared to the cross-linked hydrogel and the results showed different diffusive fronts, in particular for the peaks in the aromatic region between 7 and $6 \mathrm{ppm}$, rows with different gradient diffusion are detectable showing the signal at higher diffusion related to the furan protons of chitosan (6.3-6.1 ppm), and the signal at lower diffusion related to the furan protons of gelatin $(6.2 \mathrm{ppm})$. Furthermore, the different mobility of the two blended polymers is detectable in the anomeric region between 4.5 and $3.0 \mathrm{ppm}$ due to the different molecular weights of free chitosan and gelatin. The outcome is a different of diffusion coefficients of the blended sample, that is no more observed in the crosslinked hydrogel.

This result suggests that unreacted free polymers are absent in the solution, and the cycloaddition reaction with 4-arm-PEG10K-maleimide involved every available polymer chains. The comparison of the diffusion coefficients of the starting polymer and of the polymer treated with cross-linking agents facilitates the verification of hydrogel formation [57]. To distinguish different species, apparent self-diffusion coefficients (D) were determined. In the gelatin-chitosan hydrogel, the average value of diffusion coefficient (D) is in the order of $10-12 \mathrm{~m}^{2} / \mathrm{s}$, which is significantly reduced compared to the values of chitosan-MF and gelatin-MF or the blend (in the order of $1.10-11 \mathrm{~m}^{2} / \mathrm{s}$ ). The $\mathrm{D}$ value decreases because of the covalent bonds between the two polymers, which involve stronger linkages, stronger interactions, and then lower diffusion, as shown in Figure 4. Moreover, the figure shows how blended chitosan-MF and gelatin-MF have different diffusion coefficients (in blue), with respect to the cross-linked hydrogel (in red).

\subsection{Thermogravimetric Analysis (TGA)}

TGA results of pure and functionalized gelatin and chitosan and GelChiDA are shown in Figure 5. The gelatin curves exhibit two thermal decomposition steps. The first step occurs up to $363 \mathrm{~K}$ due to moisture weight loss. The second one takes place in the temperature range of 473-773 K, attributed to the complete breakdown of protein chains. Temperature onset and maximum degradation temperatures (Tonset and Tmax) are observed at 493 and $573 \mathrm{~K}$, respectively. In TGA curves of chitosan, besides the weight loss up to $393 \mathrm{~K}$ due to the adsorbed water, the main thermal degradation occurs in one 
step and starts at $468 \mathrm{~K}$ that is initiated by the random chain break and deacetylation. The maximum degradation temperature is reached at $508 \mathrm{~K}$ [58]. In both functionalized chitosan and gelatin, TGA analyses show a slight improvement of thermal properties as reported in Table 3.

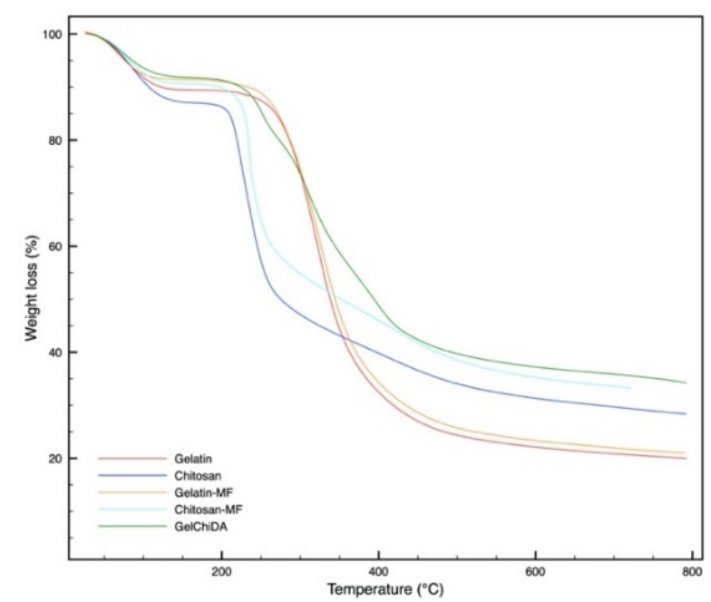

Figure 5. TGA curves of functionalized and unfunctionalized gelatin and chitosan and gelatinchitosan cross-linked hydrogel.

Table 3. TGA analysis of the starting and functionalized polymers and the hydrogel.

\begin{tabular}{ccccccc}
\hline \multirow{2}{*}{ Sample } & \multicolumn{3}{c}{ Water Desorption } & \multicolumn{3}{c}{ Degradation } \\
\cline { 2 - 7 } & Peak (K) & Range (K) & Weight Loss (\%) & Peak (K) & Range (K) & Weight Loss (\%) \\
\hline Gelatin & 348 & $300-429$ & 10.6 & 592 & $457-879$ & 67.4 \\
Gelatin-MF & 340 & $300-421$ & 8.6 & 597 & $443-877$ & 68.1 \\
Chitosan & 361 & $300-428$ & 12.9 & 499 & $453-634$ & 44.7 \\
Chitosan-MF & 349 & $300-423$ & 9.3 & 508 & $434-616$ & 40 \\
GelChiDa & 348 & $300-429$ & 8.2 & 582 & $440-923$ & 55.3 \\
\hline
\end{tabular}

TGA curves for GelChiDA are quite similar except that thermal stability is improved by cross-linking (Figure 5). The second degradation stage of hybrid hydrogel takes place at higher temperature than the corresponding stage of pure chitosan but at lower temperature compared to gelatin, indicating that the composite has in-between trend [59]. As the graph points out, the hybrid biomaterial has a lower \% weight loss at high temperatures. In other words, the product has higher thermal stability than starting materials [60].

\section{Discussion}

3D bioprinting of hybrid hydrogels is currently a hot topic and represent a valid manufacturing methodology to implement and maximize the translation of 3D tissue models for drug screening and tissue engineering applications [61,62]. GelChiDA, a hydrogel that we developed by cross-linking gelatin and chitosan, satisfies multiple critical requirements, including cell compatibility, enhanced printability, structural and chemical stability, appealing kinetics, and rheological properties. Such a complex platform has various advantages over traditional 2D cell cultures, providing an ECM-mimicking environment with better control over cell fate and signaling properties, and thus is highly promising for translational applications in biomedicine and tissue engineering [63]. It has application in translational research, however, requires in-depth characterization of the chemical and structural properties of the final 3D printable construct. A set of techniques has been proposed, achieving an in-depth and complete characterization of both the starting materials and the final construct, including the cross-linking reaction kinetics. Chemical and physical properties have been investigated employing HP-SEC-TDA, UV, FT-IR, NMR, and TGA. 
The proposed analytical strategy guarantees a relatively rapid but complete overview over the critical properties of such complex biomaterials and can be, in principle, applied to all the constructs of this nature, for both the optimization and tuning of the properties of a new material and the quality control of well-established platforms. Furthermore, the completeness and depth of characterization may provide more and useful details depending on the hydrogel investigated. For example, some of the proposed techniques such as DOSY allow to verify the absence of unreacted and undesirable by-products, which can potentially compromise the biocompatibility of the hydrogels.

Supplementary Materials: The following are available online at https: / www.mdpi.com/article/ 10.3390/biom11050683/s1, Figure S1: ${ }^{1} \mathrm{H}-\mathrm{NMR}$ —chitosan-MF, Figure S2: ${ }^{13} \mathrm{C}$ NMR—chitosan-MF, Figure S3: HSCQ—chitosan-MF, Figure S4: gHMBC—chitosan-MF, Figure S5: ${ }^{1} \mathrm{H}-\mathrm{NMR}$-gelatin-MF, Figure S6: ${ }^{13} \mathrm{C}-\mathrm{NMR}$ - gelatin-MF, Figure S7: gHMBC—gelatin-MF, Figure S8: ${ }^{1} \mathrm{H}-\mathrm{NMR}$-4-armPEG10K-Maleimide, Figure S9: ${ }^{1} \mathrm{H}-\mathrm{NMR}$-integrals of hydrogel at different timepoints.

Author Contributions: Conceptualization, S.B. and L.R. (Laura Russo); methodology, S.M., L.R. (Lorenzo Rossi), and C.C. Investigation, S.M, L.R. (Lorenzo Rossi), and C.C.; writing, review and ed-iting, S.M., L.R. (Lorenzo Rossi), F.N., S.B., and L.R. (Laura Russo); supervision, S.B. and L.R. (Laura Russo); funding acquisition, F.N. and L.R. (Laura Russo). All authors have read and agreed to the published version of the manuscript.

Funding: This research was funded by the EC, H2020-NMBP-15-2017-GA-760986 Integration of Nano- and Biotechnology for beta-cell and islet Transplantation (iNanoBIT); Italian Ministry of Health (Grant No. RF-2016-02362946); POR-FESR 2014-2020 Innovazione e Competitività; and PROGETTI STRATEGICI DI RICERCA, SVILUPPO E INNOVAZIONE, Azione I.1.b.1.3-IMMUNHUB — Sviluppo di nuove molecole di seconda generazione per immunoterapia oncologica.

Institutional Review Board Statement: Not applicable.

Informed Consent Statement: Not applicable.

Data Availability Statement: Not applicable.

Acknowledgments: The authors thanks to Silvia Mostoni for TGA analysis.

Conflicts of Interest: The authors declare no conflict of interest.

$\begin{array}{ll}\text { Abbreviations } & \\ \text { ECM } & \text { Extracellular matrix } \\ \text { MF } & \text { Methylfuran } \\ \text { GelChiDA } & \text { Gelatin-chitosan Diels Alder hybrid hydrogel } \\ \text { HP-SEC-TDA } & \begin{array}{l}\text { High-performance size exclusion chromatography on line with a triple detector } \\ \text { array }\end{array} \\ \text { NMR } & \text { Nuclear magnetic resonance } \\ \text { DOSY } & \text { Diffusion order spectroscopy NMR } \\ \text { FTIR-ATR } & \text { Fourier-transform infrared spectroscopy-attenuated total reflection } \\ \text { UV-VIS } & \text { Ultraviolet-visible spectroscopy } \\ \text { TGA } & \text { Thermogravimetric analysis }\end{array}$

\section{References}

1. Pina, S.; Oliveira, J.M.; Reis, R.L. Natural-Based Nanocomposites for Bone Tissue Engineering and Regenerative Medicine: A Review. Adv. Mater. 2015, 27, 1143-1169. [CrossRef] [PubMed]

2. Zadpoor, A.A.; Malda, J. Additive Manufacturing of Biomaterials, Tissues, and Organs State-of-the-Art Review of 3D Bioprinting for Cardiovascular Tissue Engineering. Ann. Biomed. Eng. 2017, 45, 1-11. [CrossRef] [PubMed]

3. Eslahi, N.; Abdorahim, M.; Simchi, A. Smart Polymeric Hydrogels for Cartilage Tissue Engineering: A Review on the Chemistry and Biological Functions. Biomacromolecules 2016, 17, 3441-3463. [CrossRef] [PubMed]

4. Jin, M.; Shi, J.; Zhu, W.; Yao, H.; Wang, D. Polysaccharide-Based Biomaterials in Tissue Engineering: A Review. Tissue Eng. Part B Rev. 2020. [CrossRef] 
5. Ashrafizadeh, M.; Ahmadi, Z.; Mohamadi, N.; Zarrabi, A.; Abasi, S.; Dehghannoudeh, G.; Tamaddondoust, R.N.; Khanbabaei, H.; Mohammadinejad, R.; Thakur, V.K. Chitosan-Based Advanced Materials for Docetaxel and Paclitaxel Delivery: Recent Advances and Future Directions in Cancer Theranostics. Int. J. Biol. Macromol. 2020, 145, 282-300. [CrossRef]

6. Dehshahri, A.; Kumar, A.; Madamsetty, V.S.; Uzieliene, I.; Tavakol, S.; Azedi, F.; Fekri, H.S.; Zarrabi, A.; Mohammadinejad, R.; Thakur, V.K. New Horizons in Hydrogels for Methotrexate Delivery. Gels 2020, 7, 2. [CrossRef]

7. Hinderer, S.; Layland, S.L.; Schenke-Layland, K. ECM and ECM-like Materials-Biomaterials for Applications in Regenerative Medicine and Cancer Therapy. Adv. Drug Deliv. Rev. 2016, 97, 260-269. [CrossRef]

8. Hussey, G.S.; Dziki, J.L.; Badylak, S.F. Extracellular Matrix-Based Materials for Regenerative Medicine. Nat. Rev. Mater. 2018, 3 , 159-173. [CrossRef]

9. Ashammakhi, N.; Ahadian, S.; Xu, C.; Montazerian, H.; Ko, H.; Nasiri, R.; Barros, N.; Khademhosseini, A. Bioinks and Bioprinting Technologies to Make Heterogeneous and Biomimetic Tissue Constructs. Mater. Today Bio 2019, 1, 100008. [CrossRef]

10. Mota, C.; Camarero-Espinosa, S.; Baker, M.B.; Wieringa, P.; Moroni, L. Bioprinting: From Tissue and Organ Development to in Vitro Models. Chem. Rev. 2020, 120, 10547-10607. [CrossRef]

11. Wade, R.J.; Burdick, J.A. Engineering ECM Signals into Biomaterials. Mater. Today 2012, 15, 454-459. [CrossRef]

12. Lutolf, M.P.; Hubbell, J.A. Synthetic Biomaterials as Instructive Extracellular Microenvironments for Morphogenesis in Tissue Engineering. Nat. Biotechnol. 2005, 23, 47. [CrossRef] [PubMed]

13. Khan, F.; Tanaka, M. Designing Smart Biomaterials for Tissue Engineering. Int. J. Mol. Sci. 2017, 19, 17. [CrossRef] [PubMed]

14. Nicolas, J.; Magli, S.; Rabbachin, L.; Sampaolesi, S.; Nicotra, F.; Russo, L. 3D Extracellular Matrix Mimics: Fundamental Concepts and Role of Materials Chemistry to Influence Stem Cell Fate. Biomacromolecules 2020, 21, 1968-1994. [CrossRef] [PubMed]

15. Magli, S.; Rossi, G.B.; Risi, G.; Bertini, S.; Cosentino, C.; Crippa, L.; Ballarini, E.; Cavaletti, G.; Piazza, L.; Masseroni, E.; et al. Design and Synthesis of Chitosan-Gelatin Hybrid Hydrogels for 3D Printable In Vitro Models. Front. Chem. 2020, 8, 524. [CrossRef] [PubMed]

16. Rosellini, E.; Zhang, Y.S.; Migliori, B.; Barbani, N.; Lazzeri, L.; Shin, S.R.; Dokmeci, M.R.; Cascone, M.G. Protein/PolysaccharideBased Scaffolds Mimicking Native Extracellular Matrix for Cardiac Tissue Engineering Applications. J. Biomed. Mater. Res. Part A 2018, 106, 769-781. [CrossRef]

17. Abalymov, A.; Parakhonskiy, B.; Skirtach, A. Polymer- and Hybrid-Based Biomaterials for Interstitial, Connective, Vascular, Nerve, Visceral and Musculoskeletal Tissue Engineering. Polymers 2020, 12, 620. [CrossRef]

18. Marin, E.; Boschetto, F.; Pezzotti, G. Biomaterials and Biocompatibility: An Historical Overview. J. Biomed. Mater. Res. Part A 2020, 108, 1617-1633. [CrossRef]

19. Marelli, B.; Ghezzi, C.E.; Mohn, D.; Stark, W.J.; Barralet, J.E.; Boccaccini, A.R.; Nazhat, S.N. Accelerated Mineralization of Dense Collagen-Nano Bioactive Glass Hybrid Gels Increases Scaffold Stiffness and Regulates Osteoblastic Function. Biomaterials 2011, 32, 8915-8926. [CrossRef]

20. Marsano, A.; Maidhof, R.; Wan, L.Q.; Wang, Y.; Gao, J.; Tandon, N.; Vunjak-Novakovic, G. Scaffold Stiffness Affects the Contractile Function of Three-Dimensional Engineered Cardiac Constructs. Biotechnol. Prog. 2010, 26, 1382-1390. [CrossRef]

21. Segura, T.; Anderson, B.C.; Chung, P.H.; Webber, R.E.; Shull, K.R.; Shea, L.D. Crosslinked Hyaluronic Acid Hydrogels: A Strategy to Functionalize and Pattern. Biomaterials 2005, 26, 359-371. [CrossRef]

22. Nimni, M.E.; Cheung, D.; Strates, B.; Kodama, M.; Sheikh, K. Chemically Modified Collagen: A Natural Biomaterial for Tissue Replacement. J. Biomed. Mater. Res. 1987, 21, 741-771. [CrossRef] [PubMed]

23. Lowe, A.B. Thiol-Yne 'Click' /Coupling Chemistry and Recent Applications in Polymer and Materials Synthesis and Modification. Polymer 2014, 55, 5517-5549. [CrossRef]

24. Binder, W.H.; Sachsenhofer, R. “Click” Chemistry in Polymer and Materials Science. Macromol. Rapid Commun. 2007, 28, 15-54. [CrossRef]

25. Bai, X.; Lü, S.; Cao, Z.; Ni, B.; Wang, X.; Ning, P.; Ma, D.; Wei, H.; Liu, M. Dual Crosslinked Chondroitin Sulfate Injectable Hydrogel Formed via Continuous Diels-Alder (DA) Click Chemistry for Bone Repair. Carbohydr. Polym. 2017, 166, 123-130. [CrossRef]

26. Cuvellier, A.; Verhelle, R.; Brancart, J.; Vanderborght, B.; Van Assche, G.; Rahier, H. The Influence of Stereochemistry on the Reactivity of the Diels-Alder Cycloaddition and the Implications for Reversible Network Polymerization. Polym. Chem. 2019, 10, 473-485. [CrossRef]

27. Madl, C.M.; Heilshorn, S.C. Rapid Diels-Alder Cross-Linking of Cell Encapsulating Hydrogels. Chem. Mater. 2019, 31, 8035-8043. [CrossRef]

28. Koehler, K.C.; Anseth, K.S.; Bowman, C.N.; Nimmo, C.M.; Owen, S.C.; Shoichet, M.S.; Madl, C.M.; Heilshorn, S.C.; Hall, D.J.; Van Den Berghe, H.M.; et al. Cross-Linked Hydrogels Formed through Diels-Alder Coupling of Furan- and Maleimide-Modified Poly(Methyl Vinyl Ether-Alt-Maleic Acid). Biomacromolecules 2013, 14, 1-29.

29. Montiel-Herrera, M.; Gandini, A.; Goycoolea, F.M.; Jacobsen, N.E.; Lizardi-Mendoza, J.; Recillas-Mota, M.; Argüelles-Monal, W.M. N-(Furfural) Chitosan Hydrogels Based on Diels-Alder Cycloadditions and Application as Microspheres for Controlled Drug Release. Carbohydr. Polym. 2015, 128, 220-227. [CrossRef]

30. Gandini, A. The Furan/Maleimide Diels-Alder Reaction: A Versatile Click-Unclick Tool in Macromolecular Synthesis. Prog. Polym. Sci. 2013, 38, 1-29. [CrossRef] 
31. Polgar, L.M.; Kingma, A.; Roelfs, M.; van Essen, M.; van Duin, M.; Picchioni, F. Kinetics of Cross-Linking and de-Cross-Linking of EPM Rubber with Thermoreversible Diels-Alder Chemistry. Eur. Polym. J. 2017, 90, 150-161. [CrossRef]

32. Smith, L.J.; Taimoory, S.M.; Tam, R.Y.; Baker, A.E.G.; Binth Mohammad, N.; Trant, J.F.; Shoichet, M.S. Diels-Alder Click-CrossLinked Hydrogels with Increased Reactivity Enable 3D Cell Encapsulation. Biomacromolecules 2018, 19, 926-935. [CrossRef] [PubMed]

33. Gregoritza, M.; Brandl, F.P. The Diels-Alder Reaction: A Powerful Tool for the Design of Drug Delivery Systems and Biomaterials. Eur. J. Pharm. Biopharm. 2015, 97, 438-453. [CrossRef] [PubMed]

34. Cadamuro, F.; Russo, L.; Nicotra, F. Biomedical Hydrogels Fabricated Using Diels-Alder Crosslinking. Eur. J. Org. Chem. 2021, 2021, 374-382. [CrossRef]

35. Nimmo, C.M.; Owen, S.C.; Shoichet, M.S. Diels-Alder Click Cross-Linked Hyaluronic Acid Hydrogels for Tissue Engineering. Biomacromolecules 2011, 12, 824-830. [CrossRef] [PubMed]

36. Yu, F.; Cao, X.; Li, Y.; Zeng, L.; Yuan, B.; Chen, X. An Injectable Hyaluronic Acid/PEG Hydrogel for Cartilage Tissue Engineering Formed by Integrating Enzymatic Crosslinking and Diels-Alder "Click Chemistry". Polym. Chem. 2014, 5, 1082-1090. [CrossRef]

37. Bi, B.; Ma, M.; Lv, S.; Zhuo, R.; Jiang, X. In-Situ Forming Thermosensitive Hydroxypropyl Chitin-Based Hydrogel Crosslinked by Diels-Alder Reaction for Three Dimensional Cell Culture. Carbohydr. Polym. 2019, 212, 368-377. [CrossRef]

38. Bertini, S.; Bisio, A.; Torri, G.; Bensi, D.; Terbojevich, M. Molecular Weight Determination of Heparin and Dermatan Sulfate by Size Exclusion Chromatography with a Triple Detector Array. Biomacromolecules 2005, 6, 168-173. [CrossRef]

39. Bowman, W.A.; Rubinstein, M.; Tan, J.S. Polyelectrolyte-Gelatin Complexation: Light-Scattering Study. Macromolecules 1997, 30, 3262-3270. [CrossRef]

40. Rinaudo, M.; Milas, M.; Dung, P. Le Characterization of Chitosan. Influence of Ionic Strength and Degree of Acetylation on Chain Expansion. Int. J. Biol. Macromol. 1993, 15, 281-285. [CrossRef]

41. Sultankulov, B.; Berillo, D.; Sultankulova, K.; Tokay, T.; Saparov, A. Progress in the Development of Chitosan-Based Biomaterials for Tissue Engineering and Regenerative Medicine. Biomolecules 2019, 9, 470. [CrossRef] [PubMed]

42. Tao, F.; Cheng, Y.; Shi, X.; Zheng, H.; Du, Y.; Xiang, W.; Deng, H. Applications of Chitin and Chitosan Nanofibers in Bone Regenerative Engineering. Carbohydr. Polym. 2020, 230, 115658. [CrossRef]

43. Echave, M.C.; Burgo, L.S.; Pedraz, J.L.; Orive, G. Gelatin as Biomaterial for Tissue Engineering. Curr. Pharm. Des. 2017, 23, 3567-3584. [CrossRef] [PubMed]

44. Bello, A.B.; Kim, D.; Kim, D.; Park, H.; Lee, S.-H. Engineering and Functionalization of Gelatin Biomaterials: From Cell Culture to Medical Applications. Tissue Eng. Part B Rev. 2020, 26, 164-180. [CrossRef] [PubMed]

45. Gandini, A.; Coelho, D.; Gomes, M.; Reis, B.; Silvestre, A. Materials from Renewable Resources Based on Furan Monomers and Furan Chemistry: Work in Progress. J. Mater. Chem. 2009, 19, 8656-8664. [CrossRef]

46. García-Astrain, C.; Gandini, A.; Peña, C.; Algar, I.; Eceiza, A.; Corcuera, M.; Gabilondo, N. Diels-Alder "Click" Chemistry for the Cross-Linking of Furfuryl-Gelatin-Polyetheramine Hydrogels. RSC Adv. 2014, 4, 35578-35587. [CrossRef]

47. Cui, J.; Wang, S.; Huang, K.; Li, Y.; Zhao, W.; Shi, J.; Gu, J. Conjugation-Induced Fluorescence Labelling of Mesoporous Silica Nanoparticles for the Sensitive and Selective Detection of Copper Ions in Aqueous Solution. New J. Chem. 2014, $38,6017$. [CrossRef]

48. González, R.; Figueroa, J.M.; González, H. Furfuryl Alcohol Polymerisation by Iodine in Methylene Chloride. Eur. Polym. J. 2002, 38, 287-297. [CrossRef]

49. Durand, P.-L.; Grau, E.; Cramail, H. Bio-Based Thermo-Reversible Aliphatic Polycarbonate Network. Molecules 2019, 25, 74. [CrossRef]

50. Pereira, A.G.B.; Muniz, E.C.; Hsieh, Y. Lo 1H NMR and 1H-13C HSQC Surface Characterization of Chitosan-Chitin Sheath-Core Nanowhiskers. Carbohydr. Polym. 2015, 123, 46-52. [CrossRef]

51. Alves, P.; Santos, M.; Mendes, S.; Miguel, S.P.; de Sá, K.D.; Cabral, C.S.D.; Correia, I.J.; Ferreira, P. Photocrosslinkable Nanofibrous Asymmetric Membrane Designed for Wound Dressing. Polymers 2019, 11, 653. [CrossRef] [PubMed]

52. Claaßen, C.; Claaßen, M.H.; Truffault, V.; Sewald, L.; Tovar, G.E.M.; Borchers, K.; Southan, A. Quantification of Substitution of Gelatin Methacryloyl: Best Practice and Current Pitfalls. Biomacromolecules 2018, 19, 42-52. [CrossRef] [PubMed]

53. Ding, W.; Sun, J.; Lian, H.; Xu, C.; Liu, X.; Zheng, S.; Zhang, D.; Han, X.; Liu, Y.; Chen, X.; et al. The Influence of Shuttle-Shape Emodin Nanoparticles on the Streptococcus Suis Biofilm. Front. Pharmacol. 2018, 9, 227. [CrossRef] [PubMed]

54. Kirchhof, S.; Brandl, F.P.; Hammer, N.; Goepferich, A.M. Investigation of the Diels-Alder Reaction as a Cross-Linking Mechanism for Degradable Poly(Ethylene Glycol) Based Hydrogels. J. Mater. Chem. B 2013, 1, 4855-4864. [CrossRef] [PubMed]

55. Ghanian, M.H.; Mirzadeh, H.; Baharvand, H. In Situ Forming Hydrogels Based on Clickable Star-PEG for Biomedical Applications. In Eco-friendly and Smart Polymer Systems; Springer International Publishing: Berlin/Heidelberg, Germany, 2020 ; pp. 92-95.

56. Mirzadeh, H.; Katbab, A.A. Eco-Friendly and Smart Polymer Systems; Springer International Publishing: Berlin/Heidelberg, Germany, 2020.

57. Ladiè, R.; Cosentino, C.; Tagliaro, I.; Antonini, C.; Bianchini, G.; Bertini, S. Supramolecular Structuring of Hyaluronan-LactoseModified Chitosan Matrix: Towards High-Performance Biopolymers with Excellent Biodegradation. Biomolecules 2021, 11, 389. [CrossRef] [PubMed]

58. Mohamed, M.H.; Udoetok, I.A.; Wilson, L.D.; Headley, J.V. Fractionation of Carboxylate Anions from Aqueous Solution Using Chitosan Cross-Linked Sorbent Materials. RSC Adv. 2015, 5, 82065-82077. [CrossRef] 
59. Kakkar, P.; Verma, S.; Manjubala, I.; Madhan, B. Development of Keratin-Chitosan-Gelatin Composite Scaffold for Soft Tissue Engineering. Mater. Sci. Eng. C 2014, 45, 343-347. [CrossRef] [PubMed]

60. Rusu, A.G.; Popa, M.I.; Lisa, G.; Vereştiuc, L. Thermal Behavior of Hydrophobically Modified Hydrogels Using TGA/FTIR/MS Analysis Technique. Thermochim. Acta 2015, 613, 28-40. [CrossRef]

61. Hong, N.; Yang, G.H.; Lee, J.H.; Kim, G.H. 3D Bioprinting and Its In Vivo Applications. J. Biomed. Mater. Res. Part B Appl. Biomater. 2018, 106, 444-459. [CrossRef] [PubMed]

62. Moroni, L.; Burdick, J.A.; Highley, C.; Lee, S.J.; Morimoto, Y.; Takeuchi, S.; Yoo, J.J. Biofabrication Strategies for 3D In Vitro Models and Regenerative Medicine. Nat. Rev. Mater. 2018, 3, 21-37. [CrossRef]

63. Duval, K.; Grover, H.; Han, L.H.; Mou, Y.; Pegoraro, A.F.; Fredberg, J.; Chen, Z. Modeling Physiological Events in 2D vs. 3D Cell Culture. Physiology 2017, 32, 266-277. [CrossRef] [PubMed] 